\title{
Methanol Leaf Extract of Diospyros Chloroxylon Attenuates Chlorpyrifos-Induced Toxicity in Rats
}

\author{
Adeleke $\mathrm{GE}^{1}$, Adedosu $\mathrm{OT}^{1}$, Arinde $0^{2}$, Adeyemo $\mathrm{OE}^{1}$, Bolarinwa $\mathrm{W}^{1}$, Oyewo $\mathrm{EB}^{* 1}$ \\ ${ }^{1}$ Department of Biochemistry, Faculty of Basic Medical Sciences, Ladoke Akintola University of Technology, Nigeria \\ ${ }^{2}$ Department of Biology, Kwara State College of Education (Technical), Nigeria
}

*Corresponding author: Oyewo EB, Department of Biochemistry, Faculty of Basic Medical Sciences, Ladoke Akintola University of Technology, Ogbomoso, Oyo State, Nigeria.

Received Date: February 24, 2021

Published Date: March 10, 2021

\begin{abstract}
Background and Objective: Chlorpyrifos [0, 0-diethyl-0-(3, 5, 6-trichloro-2-pyridyl)-phosphorothioate] (CPF) is a broad-spectrum Organophosphate insecticide that are used in many farms and homes. Despite the several reported toxicity in humans, there has been virtually no alternative effective insecticide. Thus, the amelioration of the toxicities seems the best option in alternative medicine. This study, therefore, investigated the effects of methanol extract of Diospyros chloroxylon leaf (MEDCL) on the brain and heart of rats exposed to CPF.

Materials and Methods: Twenty-four rats were randomized into four groups of 6 rats each, and treated separately with distilled water (Control), CPF (5 mg/kg), MEDCL (100 mg/kg) and MEDCL (100 mg/kg) + CPF (5 mg/kg), following 7 days of acclimatization. After 4 weeks of treatments, the rats were sacrificed, and the levels of Superoxide dismutase (SOD), Catalase (CAT), Malondialdehyde (MDA), reduced glutathione (GSH), Glutathione peroxidase (GPx), glutathione S-transferase (GST) and DNA fragmentation were spectrophotometrically assessed in the brain and heart, while Acetylcholinesterase (AChE) activities were assessed in the serum and brain of the rats.

Results: The results showed that CPF significantly reduced the levels of SOD, CAT, GSH, GPx and GST, while that of MDA was elevated in brain and heart, compared with controls. Treatment with CPF significantly lowered the activities of AChE in serum and brain by $94 \%$ and $48 \%$ respectively, while the level of DNA fragmentation was significantly elevated in the CPF-treated rats. Supplementation with MEDCL significantly ameliorated the changes in the rats.
\end{abstract}

Conclusion: From the foregoing, the suppressive potential of methanol extract of Diospyros chloroxylon leaf is marked indicated in brain and cardiac redox imbalance induced on exposure to Chlorpyrifos.

Keywords: Chlorpyrifos; Diospyros chloroxylon; Oxidative stress; Acetylcholinesterase; DNA fragmentation

\section{Introduction}

Chlorpyrifos $\quad[0, \quad 0$-diethyl-0-(3,5,6-trichloro-2-pyridyl)phosphorothioate] (CPF) is an organophosphate insecticide, acaricide and miticide used in protection of various crops and ornamental plants [1]. Chlorpyrifos becomes introduced into the environment via direct application on crops, lawns, domesticated animals, as well as in homes and workplaces. However, volatilization is the major way in which this organophosphate is dispersed in the environment, after application. In the environment, it becomes decomposed through the sunlight, bacterial and chemical processes
[2]. Mackay, et al. [3] has observed the atmospheric formation of Chlorpyrifos oxon from Chlorpyrifos. The hepatic biotransformation of Chlorpyrifos has been reported to involve cytochrome P-450 dependent desulfuration, to form Chlorpyrifos oxon [4,5]. This oxon is rapidly hydrolyzed to 3, 5, 6-trichloro-2-pyridinol (TCP) through the activity of Aryl- esterase. Both bioactivation and detoxification of Chlorpyrifos have been suggested to occur very rapidly, since TCP was detected as the only metabolite in the hepatic effluent under steady-state conditions 4 . The TCP has been noted to be, in 
several orders of magnitude, less toxic than either Chlorpyrifos or its oxon form $[6,7]$.

Some earlier studies by Bakke, et al. [8] and Nolan, et al. [9] had indicated that the hydrolysis of Chlorpyrifos oxon by A-esterase could probably be a common route of detoxification, since TCP or its conjugate is the major metabolite detected in rodents and humans. A kinetic study of the relative rates of deulfuration and detoxification of Chlorpyrifos by Chambers and Chambers [10] suggested a gender-dependence, which may explain its higher toxicity in female rats than male ones. Various mutagenicity studies using Chorpyrifos revealed that it could cause metaphasic chromosomal aberrations in mouse spleen cell culture [11], sister chromatid exchange in human lymphoid cells [12] and induction of micronuclei, chromosomal lesions, and DNA damage in many organisms [13-15]. However, the USEPA [16] reported the nonmutagenicity of Chlorpyrifos in both bacterial and mammalian cells but did noticed slight genetic aberrations in yeast and DNA in bacterial cells. Tumor developments in mammalian organs, such as prostate [17], breast $[18,19]$ and rectum [20] have been reported to be caused by Chlorpyrifos exposure.

The hepatic cytochrome P-450 dependent metabolism of testosterone and estradiol has been noticed to be inhibited Chlorpyrifos exposure [21,22]. Furthermore, this organophosphate insecticide has been reported to cause decrease in testicular testosterone biosynthesis, and low productions of major steroidogenic enzymes, steroidogenic acute regulatory (StAR) protein and luteinizing hormone receptor stimulated cAMP as investigated by Viswanath, et al. [23].

Diospyros choloroxylon is a widely distributed shrub, belonging to the Diospyros species of the family, Ebenaceae [24]. This shrub and some other members of the species have been used in orthodox medicine all over the world in treatments of several ailments and diseases [25-27]. Studies have shown a possible link between the medicinal potential of D. chloroxylon and the presence of secondary metabolites, such as, alkaloids, flavonoids, tannins, saponins, triterpenoids and phenolics [28]. An important triterpenoid, betulinc acid, present in Diospyros species [29], has been reported to possess several biological properties [30-35]. In the recent time, methanol extract of D. chloroxylon leaf has been reported potent against some environmental toxicants [36,37]. In the present study, the hypothesis was that methanol extract of Diospyros chloroxylon leaf could attenuate redox-induced injuries in the brain and heart of rats exposed to Chlorpyrifos.

\section{Materials and Methods}

\section{Duration and place of study}

Both experimental work and data analysis were carried out between the months of February and June 2018, in the Department of Biochemistry, Ladoke Akintola University of Technology,
Ogbomoso, Oyo State, Nigeria.

\section{Chemicals}

Glutathione, Epinephrine, 5, 5 dithiobis-(2-nitrobenzoate) (DTNB) and hydrogen peroxide were purchased from the Sigma chemical Co. Saint Louis, MO, USA. Trichloroacetic acid, 2-thiobarbituric acid, Triton X-100 and Diphenylamine were purchased from the British Drug House (BDH) Chemical td, Poole, U.K. All other reagents were of good analytical grades.

\section{Collection and extraction of Plant material}

The leaves of Diospyros chloroxylon were bought in February 2018, from a local herb seller in Ogbomoso, and authenticated at the Department of Biology, Botany Unit, Ladoke Akintola University of Technology, Ogbomoso, Oyo State, Nigeria. The leaves were washed with distilled water, air-dried, and pulverized with an electrical grinder. The leaf powder was soaked in methanol for 72 hours. The extraction was repeated twice, and the extract was collected, filtered, and concentrated under vacuum using rotary evaporator at $45 \mathrm{oC}$. The resulting crude extract was stored under refrigeration at $4 \mathrm{oC}$.

\section{Experimental animals and design}

Twenty-four (24) male Wistar rats $(140.09 \pm 9.61 \mathrm{~g})$ were bought from the Animal house of the Institute for Advanced Medical Research and Training (IAMRAT), University of Ibadan, Nigeria. The rats were later brought to the Animal house of the Department of Biochemistry, Ladoke Akintola University of Technology, Ogbomoso, Oyo State, Nigeria. They were randomized into four (4) groups (6 rats each) and housed in plastic cages and fed on rat pellets and drinking water (ad libitum) for 7 days of acclimatization, under 12 -h light/dark cycle and temperature of $29 \pm 2$ oC. The 4 groups of rats were separately treated as follows: distilled water (Control), CPF (5 mg/kg), methanol extract of D. chloroxylon leaf (MEDCL) (100 mg/kg), and CPF (5 mg/kg) + MEDCL (100mg/kg). CPF and MEDCL were administered twice per week and every other day, respectively for 4 weeks.

\section{Collection of blood and organs}

After 4 weeks, the rats were fasted overnight. Blood was collected into non-heparinized bottles by ocular bleeding and animals were sacrificed by cervical dislocation. Blood was allowed to clot and then centrifuged at $3000 \mathrm{xg}$ for 10 minutes to obtain serum. Brain and heart were excised, washed in ice-cold $1.15 \%$ potassium chloride solution to remove blood stains. Each organ was divided into 2 portions, one portion was homogenized with phosphate buffer ( $\mathrm{pH}$ 7.4) using a Teflon homogenizer and centrifuged using a high speed refrigerated centrifuge (HITACHI) at $10,000 \mathrm{xg}$ for 10 minutes to obtain homogenate used for antioxidant and Acetylcholinesterase assays. The other portion of organs was kept for DNA fragmentation assay. 


\section{Biochemical assays}

Determination of protein level: Protein levels of brain, heart and serum were determined as described by Lowry, et al. [38] using Bovine serum albumin as the standard.

Determination of malondialdehyde level: Malondialdehyde (MDA) levels of brain and heart were estimated as described by Ohkawa, et al. [39]. The absorbance of the clear pink supernatant was measured spectrophotometrically against a reference blank at $532 \mathrm{~nm}$. The MDA concentration was calculated using a molar extinction coefficient $(\varepsilon)$ of 1.56 x $105 \mathrm{M}-1 \mathrm{~cm}-1$.

Determination of superoxide dismutase activity: Superoxide dismutase activities of brain and heart were measured by the epinephrine method described by Misra and Fridovich [40]. The increase in absorbance of the assay reaction at $480 \mathrm{~nm}$ was monitored spectrophotometrically at 30 seconds intervals for 150 seconds. The specific activity of SOD was expressed in units/mg protein.

Determination of catalase activity: Catalase activities of brain and heart were assayed according to the method of Aebi [41]. The method is based on the ability of catalase to promote decomposition of hydrogen peroxide in a reaction mixture. The change in absorbance $240 \mathrm{~nm}$ was monitored spectrophotometrically at 60 seconds intervals for 180 seconds. Catalase activity was expressed as units/mg protein.

Determination of glutathione peroxidase activity: Glutathione peroxidase (GPx) activities of brain and heart were determined using the method described by Andersen, et al. [42]. The assay is based on the reaction of organic peroxide in a reaction mixture and oxidation of reduced glutathione (GSH) to form disulfide glutathione (GSSG). The GSSG is later reduced to GSH by glutathione reductase and NADPH. The decrease in absorbance at $412 \mathrm{~nm}$ is directly proportional to the GPx activity, which is expressed in $\mu \mathrm{mol} / \mathrm{mg}$ protein $/ \mathrm{min}$.

Determination of reduced glutathione level: Reduced Glutathione (GSH) levels of brain and heart were determined using the method of Mitchell, et al. [43]. The assay is based on the oxidation of GSH by sulfhydryl reagent DTNB, to form a yellow derivative, 51-thio-2-nitrobenzoic acid, with an absorbance at 412 nm. GSH level is proportional to absorbance at $412 \mathrm{~nm}$. Values were

\section{Results}

\section{Effect of MEDCL on body weight of CPF-exposed rats}

Table 1: Effect of methanol extract of Diospyros chloroxylon leaf on body weights of rats exposed to Chlorpyrifos.

\begin{tabular}{|c|c|c|c|}
\hline Treatments & Final weight $(\mathbf{g})$ & Initial weight $(\mathbf{g})$ & Weight Gain $(\mathbf{g})$ \\
\hline Control & $150.59 \pm 3.9$ & $114.62 \pm 6.8$ & $35.97 \pm 2.7$ \\
\hline CPF & $132.56 \pm 3.6$ & $128.30 \pm 4.1$ & $10.26 \pm 1.9^{\mathrm{a}}$ \\
\hline MEDCL & $140.10 \pm 5.4$ & $108.40 \pm 3.6$ & $31.70 \pm 4.7$ \\
\hline CPF+MEDCL & $147.17 \pm 2.2$ & $119.97 \pm 4.2$ & $27.20 \pm 2.6^{\mathrm{b}}$ \\
\hline
\end{tabular}

Data expressed in mean $\pm S D, n=6$, a statistically different from control $(p<0.05)$, b statistically different from CPF ( $p<0.05)$, CPF-Chlorpyrifos, MEDCL- Methanol extract of Diospyros chloroxylon leaf 
The effects of Chlorpyrifos (CPF) on the body weights of the rats are presented in Table 1 . Treatment with CPF significantly $(\mathrm{p}<0.05)$ reduced the body weight gain (in grammes) of the rats $(10.26 \pm 1.9)$ relative to the control $(35.97 \pm 2.7)$. In the MEDCL-supplemented rats, the weight gain was significantly increased $(27.20 \pm 2.6 \mathrm{~g})$ compared with the CPF-treated group.

\section{Effects of MEDCL on oxidant parameters of CPF-exposed rats}

Table 2: Effects of Diospyros chloroxylon leaf on Superoxide dismutase and Catalase activities in brain and heart of rats exposed to Chlorpyrifos.

\begin{tabular}{|c|c|c|c|c|}
\hline \multirow{2}{*}{ Treatments } & \multicolumn{2}{|c|}{ SOD (U/mg protein) } & \multicolumn{2}{|c|}{ Catalase (U/mg protein) } \\
\hline & Brain & Heart & Brain & Heart \\
\hline Control & $5.14 \pm 1.2$ & $3.54 \pm 1.0$ & $6.88 \pm 1.5$ & $3.93 \pm 0.4$ \\
\hline $\mathrm{CPF}$ & $2.30 \pm 1.3^{\mathrm{a}}$ & $1.85 \pm 0.6^{\mathrm{a}}$ & $3.91 \pm 1.2^{\mathrm{a}}$ & $3.38 \pm 1.0$ \\
\hline MEDCL & $4.51 \pm 1.8$ & $4.10 \pm 1.6$ & $7.46 \pm 0.9$ & $3.56 \pm 0.7$ \\
\hline $\mathrm{CPF}+\mathrm{MEDCL}$ & $4.68 \pm 1.6^{b}$ & $3.14 \pm 0.6^{b}$ & $7.13 \pm 0.8^{b}$ & $4.13 \pm 0.4$ \\
\hline
\end{tabular}

Data expressed in mean $\pm S D, n=6$, a statistically different from control $(p<0.05)$, b statistically different from CPF $(p<0.05)$, CPF-Chlorpyrifos, MEDCL- Methanol extract of Diospyros chloroxylon leaf.

The data in Table 2 show that CPF significantly $(\mathrm{p}<0.05)$ reduced the activity of SOD $(2.30 \pm 1.3$ and $1.85 \pm 0.6 \mathrm{U} / \mathrm{mg}$ protein $)$ versus control $(5.14 \pm 1.2$ and $3.54 \pm 1.0)$ in both brain and heart, respectively. Furthermore, the catalase activities were reduced (3.91 \pm 1.2 and $3.38 \pm 1.0 \mathrm{U} / \mathrm{mg}$ protein) versus control $(6.88 \pm 1.5$ and $3.93 \pm 0.4 \mathrm{U} / \mathrm{mg}$ protein) in brain and heart, respectively. Interestingly, supplementation with MEDCL significantly elevated the activities of SOD (4.68 \pm 1.6 and $3.14 \pm 0.6 \mathrm{U} / \mathrm{mg}$ protein) and Catalase ( $7.13 \pm 0.8$ and $4.13 \pm 0.4 \mathrm{U} / \mathrm{mg}$ protein) in brain and heart, respectively relative to the $\mathrm{CPF}$ group.
The present study also examined the effects of the treatments on levels of lipid peroxidation (MDA) and reduced glutathione (GSH), as well as the activities of glutathione peroxidase (GPx) and glutathione S-transferase (GST) in the rats. Treatment with CPF caused the level of MDA to significantly $(\mathrm{p}<0.05)$ increase (6.51 \pm 1.0 and $1.25 \pm 0.3 \mu \mathrm{M}$ MDA/ mg protein) in the brain and heart, respectively compared with control treatment $(3.48 \pm 0.4$ and $0.66 \pm 0.1 \mu \mathrm{M} \mathrm{MDA} / \mathrm{mg}$ protein). On supplementation with MEDCL, significantly lower levels of MDA were found as $2.95 \pm 0.7$ and $0.75 \pm 0.2 \mu \mathrm{M} \mathrm{MDA} / \mathrm{mg}$ protein) in brain and heart, respectively compared with the CPF-treated rats (Figure 1).

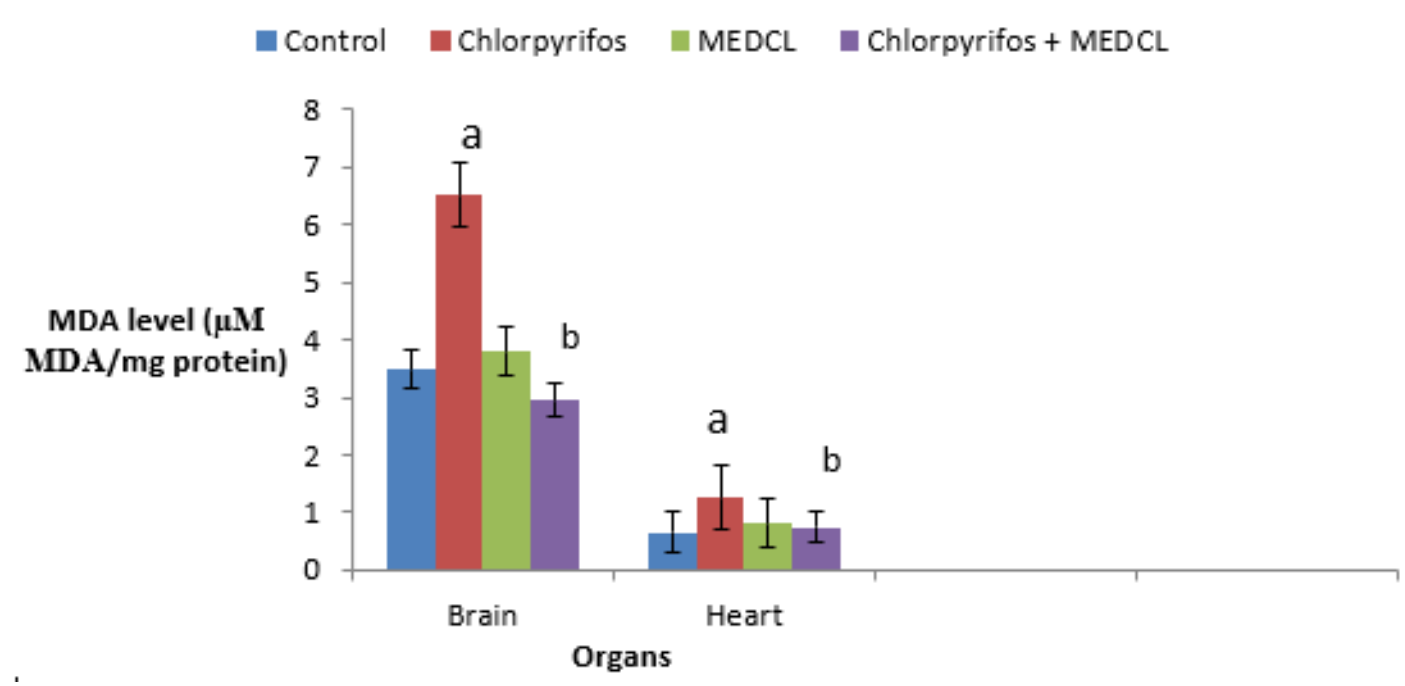

Figure 1: Effect of methanol extract of Diospyros chloroxylon leaf on Malondialdehyde (MDA) level in brain and heart of rats exposed to Chlorpyrifos.

Data expressed in mean $\pm S D, n=6$, a statistically different from control $(p<0.05)$, b statistically different from CPF $(p<0.05)$, CPFChlorpyrifos, MEDCL- Methanol extract of Diospyros chloroxylon leaf.

The level of GSH was significantly $(\mathrm{p}<0.05)$ reduced by CPF administration in both brain $(11.62 \pm 03 \mathrm{U} / \mathrm{mg}$ protein) and heart $(9.74 \pm 10 \mathrm{U} / \mathrm{mg}$ protein) as against the controls $(18.77 \pm 14$ and $15.56 \pm 12 \mathrm{U} / \mathrm{mg}$ protein), respectively. When MEDCL was administered, the levels were elevated, and found to be $17.51 \pm 3.2$ and $15.91 \pm 1.8 \mathrm{U} / \mathrm{mg}$ protein, in brain and heart, respectively compared with the CPF group, as shown in (Figure 2). 


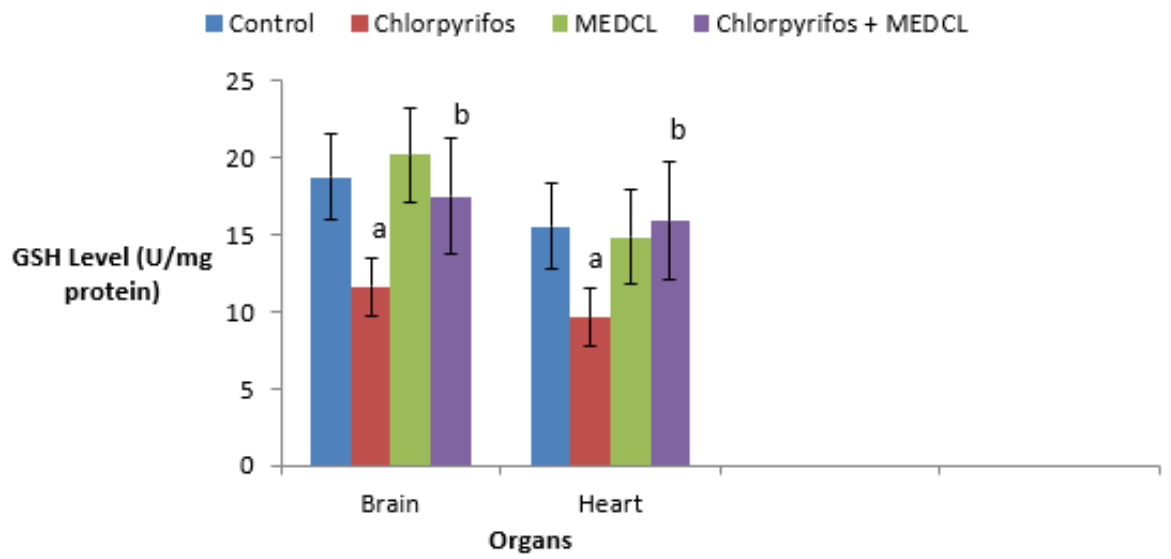

Figure 2: Effect of methanol extract of Diospyros chloroxylon leaf on reduced glutathione (GSH) level in brain and heart of rats exposed to Chlorpyrifos.

Data expressed in mean $\pm S D, n=6$, a statistically different from control $(p<0.05)$, ${ }^{b}$ statistically different from CPF $(p<0.05)$, CPF-Chlorpyrifos, MEDCL- Methanol extract of Diospyros chloroxylon leaf.

Table 3 presents the results on GPx and GST activities during the treatments. Chlorpyrifos was observed to significantly ( $p<$ $0.05)$ reduce GPx activity in brain $(6.74 \pm 1.0 \mathrm{U} / \mathrm{mg}$ protein) and heart $(2.13 \pm 0.5 \mathrm{U} / \mathrm{mg}$ protein) relative to the respective controls (8.47 \pm 2.1 and $3.48 \pm 1.2 \mathrm{U} / \mathrm{mg}$ protein). However, supplementation with MEDCL significantly attenuated the CPF- induced effects in the two organs, as shown in Table 3. Furthermore, CPF was found to significantly $(\mathrm{p}<0.05)$ reduce GST activities in the brain $(2.75 \pm 0.8 \mu \mathrm{M} / \mathrm{mg}$ protein) and heart $(1.13 \pm 0.2 \mu \mathrm{M} / \mathrm{mg}$ protein) compared with the control rats $(5.04 \pm 1.2$ and $2.48 \pm 0.9 \mu \mathrm{M} / \mathrm{mg}$ protein, respectively) as shown in table 3 . On supplementation with MEDCL, the activities were found to be $4.05 \pm 1.4$ and $2.98 \pm 0.8 \mu \mathrm{M} /$ mg protein in the respective organs compared with the CPF-treated rats.

\section{Effects of MEDCL on Acetylcholinesterase activity and DNA fragmentation in CPF-exposed rats}

Table 3: Effects of methanol extract of Diospyros chloroxylon leaf on Glutathione peroxidase (GPx) and Glutathione S- transferase (GST) activities in brain and heart of rats exposed to Chlorpyrifos.

\begin{tabular}{|c|c|c|c|c|}
\hline \multirow{2}{*}{ Treatments } & \multicolumn{2}{|c|}{ GPx ( $\mu \mathrm{M} / \mathrm{mg}$ protein/min) } & \multicolumn{2}{|c|}{ GST $(\mu \mathrm{M} / \mathrm{mg}$ protein $/ \mathrm{min})$} \\
\hline & Brain & Heart & Brain & Heart \\
\hline Control & $8.47 \pm 2.1$ & $3.48 \pm 1.2$ & $5.04 \pm 1.2$ & $2.48 \pm 0.9$ \\
\hline $\mathrm{CPF}$ & $6.74 \pm 1.0^{\mathrm{a}}$ & $2.13 \pm 0.5^{\mathrm{a}}$ & $2.75 \pm 0.8^{a}$ & $1.13 \pm 0.2^{\mathrm{a}}$ \\
\hline MEDCL & $9.16 \pm 1.4$ & $4.71 \pm 1.6$ & $4.87 \pm 1.3$ & $2.64 \pm 0.7$ \\
\hline CPF+MEDCL & $7.78 \pm 2.1^{\mathrm{b}}$ & $4.28 \pm 0.7^{b}$ & $4.05 \pm 1.4^{\mathrm{b}}$ & $2.98 \pm 0.8^{\mathrm{b}}$ \\
\hline
\end{tabular}

Data expressed in mean $\pm S D, n=6$, a statistically different from control $(p<0.05)$, b statistically different from CPF $(p<0.05)$, CPF-Chlorpyrifos, MEDCL- Methanol extract of Diospyros chloroxylon leaf.

Figure 3: Effect of methanol extract of Diospyros chloroxylon leaf on Acetylcholinesterase (AChE) activity in brain and heart of rats exposed to Chlorpyrifos.

Data expressed in mean $\pm S D, n=6$, a statistically different from control $(p<0.05)$, b statistically different from CPF $(p<0.05)$, CPFChlorpyrifos, MEDCL- Methanol extract of Diospyros chloroxylon leaf 
The result in Figure 3 shows that CPF treatment caused the AChE activities to significantly $(\mathrm{p}<0.05)$ decrease in brain $(0.11 \pm 0.0$ $\mathrm{U} / \mathrm{ml})$ and heart $(0.18 \pm 0.1 \mathrm{U} / \mathrm{ml})$, when compared with the control treatment $(0.19 \pm 0.1$ and $0.25 \pm 0.0 \mathrm{U} / \mathrm{ml})$. When supplemented with
MEDCL, the activities of AChE enzyme were observed to be $0.21 \pm$ $0.1 \mathrm{U} / \mathrm{ml}$ (brain) and $0.24 \pm 0.0 \mathrm{U} / \mathrm{ml}$ (heart) in the experimental rats. The result of the effect of CPF on the percentage of DNA fragmentation in the two organs has been presented in (Figure 4).

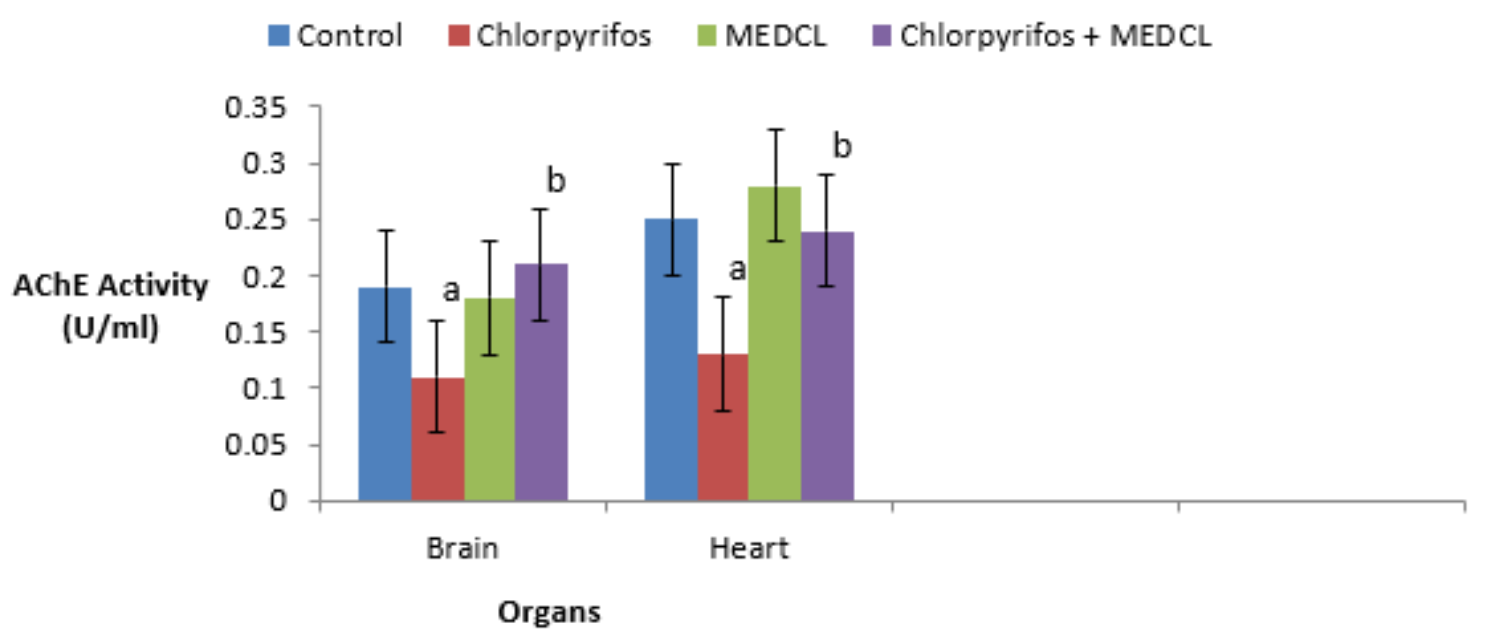

Figure 4: Effect of methanol extract of Diospyros chloroxylon leaf on DNA fragmentation in brain and heart of rats exposed to Chlorpyrifos. Data expressed in mean $\pm S D, n=6$, a statistically different from control $(p<0.05)$, b statistically different from CPF $(p<0.05)$, CPFChlorpyrifos, MEDCL- Methanol extract of Diospyros chloroxylon leaf

Treatment with CPF significantly $(\mathrm{p}<0.05)$ elevated the level of fragmented DNA in brain $(49.51 \pm 2.4 \%)$ and heart $(64.78 \pm 5.3$ $\%)$, compared with the controls $(28.47 \pm 3.1$ and $32.50 \pm 3.8$ $\%$, respectively). Interestingly, supplementation with MEDCL significantly attenuated the CPF-induced DNA damage in brain $(30.90 \pm 3.2 \%)$ and heart $(44.20 \pm 5.1 \%)$ in the rats.

\section{Discussion}

The major findings in the present study include induction of oxidative stress, DNA damage and inhibition of Acetylcholinesterase activity in rats exposed to Chlorpyrifos. Interestingly, these adverse changes were attenuated on treatment of the experimental rats with methanol extract of Diospyros chloroxylon leaf (MEDCL).

The rats exposed to CPF were noticed with a significant reduction in body weight gain, while on supplementation with the extract, the effect was improved comparable to the control animals. Studies conducted by Perera, et al. [47] and Whyatt, et al. [48] found a correlation between CPF intoxication and reduced birth weight and body length. This reduction may be a result of loss of appetite, malabsorption, and digestive disorder, as reported by Neuget, et al. [49].

Oxidative stress results from the imbalance between the reactive oxygen species (ROS) and antioxidant defence system of the cells, causing oxidation of DNA, protein, or lipid molecules. The damage, in turn, may result in several events, such as, altered gene expression [50], enhanced cell proliferation [51], genomic or chromosome instability, genetic mutation or tumour development $[52,53]$.

The data from this study showed that SOD and catalase activities were significantly reduced in both brain and heart on exposure of the rats to CPF. Malondialdehyde (MDA) is a reactive aldehyde formed because of the reaction of ROS with polyunsaturated fatty acids [54]. The elevated level of MDA indicates an induction of lipid peroxidation, hence oxidative damage in the organs of the CPFtreated animals. The toxicant also significantly reduced the levels of GSH, GPx and GST in the two organs of the animals compared with the controls. In several tissues, including brain, liver, and testis, $\mathrm{CPF}$ has been demonstrated to cause increase in lipid peroxidation (MDA level) $[55,56]$ and decrease in catalase, SOD, GPx and GST [57-60]. According to Bebe and Panemangalore [61], low doses of CPF were demonstrated to cause decrease in GSH and increase in GPx, although the level of GSH was found to increase during treatment with higher CPF doses.

Catalase is an endogenous antioxidant enzyme capable of removing ROS via conversion of hydrogen peroxide to water and oxygen [62], while GPx are a group of seleno-proteins involved in cellular protection against oxidative damage induced by hydrogen peroxide and organic peroxides [63]. Reduced glutathione (GSH), on the other hand, serves as a substrate for glutathione peroxidase (GPX) during detoxification, by being oxidized to GSH disulfide (GSSG). The GSSG is converted back to which is converted back to GSH through the activity of glutathione reductase (GPR) [64]. 
Decrease in level of GSH has been associated with low availability of cysteine molecules required for GSH production, which in turn has resulted from defect in transulfuration characteristic of liver damage [64].

Glutathione-S-transferases (GSTs) belong to a major group of phase II detoxification enzymes, responsible for the conjugation of several endogenous and exogenous reactive electrophiles with GSH [65]. Inhibition of GST activity has been suggested by Binkova, et al. [66] as a mechanism of potentiating the toxicity of environmental chemicals, resulting in increased interactions between them (or their metabolites) and cellular macromolecules. In rats and mouse, CPF is bioactivated in the liver, through cytochrome-p450-dependent pathway, to form CPF-oxon $[67,68]$, which is a more toxic metabolite. The observed reduction in the activities of the antioxidant enzymes in the present study may thus indicate the inhibitory influence of CPF-oxon, which has therefore enhanced accumulation of ROS, leading to oxidative imbalance in the two organs of the rats. This finding is supported by a study carried out by Ventura, et al. [19], who reported that Chlorpyrifos caused increase in the level of ROS in certain breast cancer cell lines. Furthermore, CPF has been demonstrated to induce oxidative stress in rat testes, leading to reductions in sperm count, systemic testosterone, gonadotropin levels and activities of enzymes catalysing spermatogenesis [69]. In the group of animals supplemented with MEDCL, the activities of the antioxidant enzymes were significantly improved, while the level of MDA was reduced relative to the toxicant group. In a recent study, betulinic acid, a triterpenoid reported to be present in Diospyros species [29], has been demonstrated to improve the activities of SOD, Catalase, GPx and GST, as well as the level of MDA in experimental rats treated with an environmental toxicant34. This thus suggests the potential of the Diospyros chloroxylon leaf extract used in this study to ameliorate the imbalance in antioxidant status of the rats.

The present study also examined the effects of CPF on the Acetylcholinesterase (AChE) activities in the brain and serum of the experimental animals. Significantly decreased activities of the enzyme were observed in rats treated with CPF relative to control rats. In several studies, CPF treatment was shown to cause neurological effects such as, sensory loss, memory impairment and depression in AChE activities in many animal species [70-72]. In a study by Cutler, et al. [73], it has been shown that CPF itself is not a potent inhibitor of AChE, but its metabolite, CPF-oxon. This metabolite phosphorylates the serine hydroxyl group at the active site of AChE enzyme, through a nucleophilic interaction, resulting in accumulation of acetylcholine, with subsequent neurotransmission disruption and death [74]. Some other studies have revealed that in the earliest stage of brain and central nervous system development, CPF mitigated neural formation, and caused reduction in the cholinergic projections [75]. This resulted in reduced neural connections, cell signalling capacity, and eventual deficiency in cholinergic synaptic response with behavioural problems in adolescence and adulthood [76]. However, CPF has been demonstrated to preferentially exert toxicity in brain glial cells, which are formed later than the neuronal cells $[77,78]$. Furthermore, this toxicant exerted adverse effects on the proliferation, differentiation and functioning of glial cells, as well as the cells involved in the neuronal metabolism and targeting within the CNS in rats, during prenatal and postnatal exposures [19,79]. In addition, Sandoval et al [80] have reported that CPF could induce generation of astroglial cells, using human neural stem cells (hNSCs) line, without affecting neuron formation. However, this study has demonstrated that supplementation with MEDCL against CPF treatment improved the activity of AChE enzyme in both brain and serum of the rats, indicating the potential of the extract in improving cholinergic transmission in the rats.

The genotoxic effect of $\mathrm{CPF}$ in the brain and heart of the rats was also examined by determining the level of DNA fragmentation as described by $\mathrm{Wu}$, et al. [46]. The treatment with CPF caused a significant increase in DNA fragmentation compared with the controls. Interestingly, the ability of MEDCL to lower the amount of fragmented DNA against CPF treatment was observed. Various forms of genotoxic effect of CPF have been reported, including bone marrow micronuclei induction and DNA hypomethylation in mouse [15], chromosomal alterations, chromosomal breaks, and sister chromatid exchange in humans [81], and micronuclei induction and chromosomal lesions in erythrocytes [82]. The reduction in the level of DNA fragmentation by MEDCL, as observed in this study shows the potential of the extract to protect the organs from the DNA damaging effect of CPF. The overall findings have implied the potential of methanol extract of Diospyros chloroxylon leaf in ameliorating the toxic effects of chlorpyrifos in experimental rats. The study thus clearly shows the possible application of Diospyros chloroxylon leaf extract in the discovery of drugs against toxicity induced by environmental agents. It could therefore be recommended that Pharmaceutical Scientists could isolate, and work on, the active ingredients of Diospyros chloroxylon leaf, for the purpose of making a drug potent against oxidative and degenerative diseases. However, this study has some limitations in that only methanol was used for extraction, and the various compounds in the MEDCL were not elucidated.

\section{Conclusion}

The data from this study have shown that Chlorpyrifos (CPF) induced significant oxidative, neurotoxic and genotoxic damage in brain and heart of experimental rats. However, methanol extract of Diospyros chloroxylon leaf ameliorated the CPF-induced redox imbalance in the two organs of rats. Furthermore, the extract of Diospyros chloroxylon leaf exerted attenuation against the 
neurotoxic and DNA-damaging effects induced by chlorpyrifos in the experimental rats.

\section{Significance Statement}

This study discovered the potential of Diospyros chloroxylon leaf extract, which could be beneficial for treatments of oxidative and degenerative diseases induced by chlorpyrifos. This study will assist researchers towards the use of Diospyros chloroxylon leaf for drug discovery, which has not been previously explored. As a result, a new theory on treatments of oxidative and degenerative diseases, using Diospyros chloroxylon leaf may be put forth, in addition to the existing data on medicinal values of plants.

\section{List of Abbreviations}

CPF: Chlorpyrifos, MEDCL: Methanol extract of Diospyros chloroxylon leaf, SOD: Superoxide dismutase, CAT: Catalase, MDA: Malon-di-aldehyde, GSH: Reduced Glutathione, Gpx: Glutathione peroxidase, GST: Glutathione S-Transferase, AChE: Acetylcholinesterase, ROS: Reactive Oxygen Species

\section{Ethical Approval and Consent to Participate}

This study was carried out in accordance with ethical laws on animal handling.

\section{Availability of Data and Materials}

The dataset supporting the conclusions of this article are included as tables and figures in the within the article (and its additional files).

\section{Authors Contributions}

AGE conceived, designed and supervised the study. AOT cosupervised the study and read the final manuscript. AOO, AOE and BW provided the materials used in the study, collated literatures and performed the experimental procedures. EBO did the statistical analyses and drafted the manuscript. All authors financed of the study. All authors read and approved the final manuscript with the order of author's names.

\section{Acknowledgement}

We appreciate the immense efforts and laboratory assistance of Dr. R. A. Ajani (LAUTECH) and the technical inputs of the Bridge Scientific Limited.

\section{Consent for Publication}

Not applicable.

\section{Competing Interest}

Not applicable.

\section{References}

1. Fang H, YL Yu, W Wang, M Shan, XM Wu, et al. (2006) Dissipation of chlopyrifos in pakchoi-vegetated soil in a greenhouse. J Environ Sci (China) 18(4): 760-764.
2. Anderson DJ, RA Hites (1988) Chlorinated pesticides in indoor air Environ Sci Technol 22 (6): 717-720.

3. Mackay D, JP Giesy, KR Solomon (2014) Fate in the environment and long-range atmospheric transport of the organophosphorous pesticide, chlopyrifos and its oxon. Rev Environ Contam Toxicol 231: 35-76.

4. Sultatos LG, SD Murphy (1983) Kinetic analyses of the microsomal biotransformation of the phosphotprothioate insecticides, chlopyrifos and parathion. Fundam Appl Toxicol 3(1): 16-21.

5. Ma T, JE Chambers (1994) Kinetic parameters of desulfuration and dearylation of parathion and chlopyrifos by rat liver microsomes. Food Chem Toxicol 32(8): 763-767.

6. Giesy JP, KR Solomon, JR Coates, KR Dixon, JM Giddings, et al. (1999) Chlopyrifos: ecological risk assessment in North American aquatic environments. Rev Environ Contam Toxicol 160: 1-129.

7. USAEPA (1999) Interim guidance on honeybee data requirements. United States Environmental Protection Agency, Washington, USA.

8. Bakke JE, VJ Fell, CE Price (1976) Rat urinary metabolites from O, 0-diethyl-0 (3, 5, 6-trichloro-2-pyridyl) phosphorothioate. J Environ Sci Health B 11(3): 225-230.

9. Nolan RJ, DL Rick, NL Freshour, JH Saunders (1984) Chlorpyrifos pharmacokinetics in human volunteers. Toxicol Appl Pharmacol 73(1): 8-15.

10. Chambers JE, HW Chambers (1989) Oxidative desulfuration of Chlorpyrifos, chlorpyrifos-methyl and leptophos by rat brain and liver. J Biochem Toxicol 4(3): 201-203.

11. Amer SM, FAE Aly (1992) Cytogenic effects of pesticides IV. Cytogenic effects of the inse3cticides, Gardona and Dursban. Mutat Res 279(3): 165-170.

12. Sobti RC, A Krishan, CD Pfaffenberger (1982) Cytokinetic and cytogenetic effects of some agricultural chemicals on human lymphoid cells in vitro: Organophosphates. Mutat Res 102(1): 89-102.

13. Ali D, NS Nagpure, R Kumar, B Kushwaha, Sudhir Kumar (2008) Genotoxicity assessment of acute exposure of chlorpyrifos to freshwater fish Channa punctatus (Bloch) using micronucleus assay and alkaline single-cell electrophoresis. Chemosphere 7: 1823-1831.

14. Yin XH, GN Zhu, XB Li, SY Liu (2009) Genotoxicity evaluation of chlorpyrifos to amphibian Chinese toad (Amphibian: Anura) by Comet assay and micronucleus test. Mutat Res 680(1-2): 2-6.

15. Cui Y, J Guo, Z Chen, Bujin Xu, (2011) Genotoxicity of chlorpyrifos and cypermethrin in ICR mouse lymphocytes. Toxicol Mech Methods 21(1): $70-74$

16. USAEPA (2009) Chlrpyrifos summary Document Registration Review: Initial Docet Number; EPA-HQ-OPP-2008-0850. United States Environmental Protection Agency, Washington, USA.

17. Alavanja MCR, C Samanic, M Dosemeci, J Lubin, R Tarone, et al. (2003) Use of Agricultural pesticides and prostate cancer risk in the Agricultural Heaith Study cohort. Am J Epidemiol 157(9): 800-814.

18. Engel LS, DA Hill, JH Lubin, CF Lynch, J Pierce, et al. (2005) Pesticide use and breast cancer risk among farmer's wives in the Agricultural Health Study. Am J Epiemiol 161(2): 121-135.

19. Ventura C, M Nunez, N Miret, DM Lamas, A Randi, et al. (2012) Differential mechanisms of actions are involved in chlorpyrifos effects in estrogendependent or-independent breast cancer cells exposed to low or high concentrations of the pesticide. Toxicol Letts 2213(2): 184-193.

20. Lee WJ, DP Sandler, A Blair, C Samanic, AJ Cross, et al. (2007) Pesticide use and colorectal cancer risk in the Agricultural Health Study. Int J Cancer 121(2): 339-346.

21. Usmani KA, RL Rose, E Hodgson (2003) Inhibition and activation of the human liver and human cytochrome p450 3A4 metabolism of testosterone by deployment-related chemicals. Drug Metabol Dispos 31(4): 384-391. 
22. Usmani KA, TM Cho, RL Rose, E Hodgson (2006) Inhibition of the human liver microsomal and human cytochrome p450 1A2 and 3A4 metabolism of estradiol by deployment-related and other chemicals. Drug Metabol Dispos 34(9): 1606-1614.

23. Viswanath G, S Chatterjee, S Dabral, SR Nanguneri, G Divya, et al. (2010) Anti-androgenic endocrine disrupting activities of chlorpyrifos and piperophos. J Steroid Biochem Mol Biol 120(1): 22-29.

24. Yonemori K, A Sugimura, M Amada (2000) Persimmon genetics and breeding. Plant Breed Rev 19: 191-225.

25. Adzu B, S Amos, S Dzarma, I Muazzam, KS Gamaniel (2002) Pharmacological evidence favouring the folkloric use of Diospyros mespiliformis Hochst in the relief of pain and fever. J Ethnopharmaco 82(2-3): 191-195.

26. Trongsakul S, A Panthong, D Kanjanapothi, T Taesotikul (2003) The analgesic, antipyretic and anti-inflammatory activities of Diospyros variegate Kruz. J Ethnopharmacol 85(2-3): 221-225.

27. Reddy KN, G Trimurthulu, SC Reddy (2008) Medicinal plants used by ethnic people of Medak district, Andhra Pradesh. Indian J Traditional Knowledge 9(1): 184-190.

28. Kim DS, Z Chen, VT Nguyen, JM Pezzuto, LU Qius, et al. (1997) A concise semi-synthetic approach to Betulinic acid from Betulin. Synth commun 27(9): 1607-1612.

29. Higa M, K Ogihara, N Yogis (1998) Bioactive naphthoquinone derivatives from dispyros maritime blume. Chem Pharm bull 46: 1189-1193.

30. Ehrhardt H, S Fulda, M Fuhrer, KM Debatin, I Jeremias (2004) Betulinic acid induced apoptosis in leukemia cells. Leukemia 18(8): 1406-1412.

31. Fulda S (2008) Betulinic acid for cancer treatment and prevention. Int Mol Sci 9(6): 1096-1107.

32. Chintharlapalli S, S Papineni, P Lei, S Pathi, S Safe (2011) Betulinic acid Inhibits colon cancer cell and tumor growth and induces proteasome: dependent and independent down regulation of specificity proteins (sp) transcription factors. BMC Cancer 11: 371.

33. Adeleke GE, OA Adaramoye (2016) Modulatory role of Betulinic acid in $\mathrm{N}$-nitrosodimethy lamine-induced toxicity in male rats. Hum and Exper Toxicol Pp:1-10.

34. Adeleke GE, OA Adaramoye (2017) Betulinic acid protects against $\mathrm{N}$-nitrosodimethylamine-induced redox imbalance in testes of rats Redox Rep 22(6): 556-562.

35. Adeleke GE, JA Badmus, OT Adedosu, DH Abioye, OO Arinde (2018) Betulinic acid attenuates hepatic and testicular redox imbalance and DNA damage in male rats exposed to crude oil. J Pharmacog and Phytochem 7(3): 316-322.

36. Adeleke GE, OT Adedosu, OA Adaramoye, AS Olagunju, OJ Teibo, et al. (2016) Hepatoprotective effect of methanol extract of Diospyros chloroxylon leaf in $\mathrm{N}$-Nitrosodimethylamine-induced hepatotoxicity in Wistar rats. As J Health Sci 3(3): 142-152.

37. Adeleke GE, OT Adedosu, OK Afolabi, OO Arinde, TM Oyedokun (2017) Methanolic extract of Diospyros chloroxylon modulates hepatic redox profile and cell proliferation in Dimethylamine-treated rats. Br J Med and Med Res 21(2): 1-12

38. Lowry OH, Rosbrough NJ, Farr AL (1951) Protein measurement with the Folin-phenol reagent. J Biol Chem 193(1): 265-275.

39. Ohkawa H, N Ohishi, K Yagi (1979) Assay for lipid peroxides in animal tissues by thiobarbituric acid reaction. Anal Biochem 95(2): 351-358.

40. Misra HP, J Fridovich (1972) The role of superoxide anion in the autoxidation of epinephrine and a simple assay for superoxide dismutase. J Biol Chem 247(10): 3170-3175.

41. Aebi H (1984) Catalase in vitro. In: Methods in Enzymology by Packer L (Ed.), Orlando, 105: 121-126.
42. Andersen HR, JB Nielsen, F Nielsen, P Grandjean (1997) Antioxidative enzyme activities in human erythrocytes. Clin Chem 43(4): 562-568.

43. Mitchell JR, DJ Jollow, WZ Potter, D C Davis, J R Gillette, et al. (1973) Acetaminophen-induced hepatic necrosis I Role of drug metabolism. J Pharmacol Exp Therap 187(1): 185-194

44. Habig W, M Pabst, W Jakoby (1974) Glutathione S-transferases: The first enzymatic step in mercapturic acid formation. J Biol Chem 249(22): 7130-7139.

45. Ellman GL, KD Courtney, V Jr Andres, Y Featherstone (1961) A new and rapid colorimetric determination of acetylcholinesterase activity. Biohem Pharmacol 7: 88-95.

46. Wu B, A Ootani, R Iwakiri, Y Sakata, T Fujise, et al. (2005) T-cell deficiency leads to liver carcinogenesis in Azoxymethane-treated rats. Exp Biol Med 231(1): 91-98.

47. Peerera FP, V Rauh, WY Tsai, P Kinney, D Camann, et al. (2003) Effects of transplacental exposure to environmental pollutants on birth outcomes in a multiethnic population. Environ Health Perspect 111(2): 201-205.

48. Whyatt RM, V Rauh, DB Barr, D Camann, HF Andrews, et al. (2004) Prenatal insecticide exposures and birth weight and length among an urban minority cohort. Environ Health Perspect 112(10): 1125-1132.

49. Neuget AL, Katherine D Crew (2006) Epidemiology of gastic cancer World J Gastroenterol 12(3): 354-362.

50. Allen RG, M Tresini (2000) Oxidative stress and gene regulation. Free Radic Biol Med 28(3): 463-499.

51. Toyokuni S (2006) Novel aspects of oxidative stress-associated carcinogenesis. Antioxid Redox Signal 8(7-8): 1373-1377.

52. Ishikawa K, K Takenaga, M Akimoto, N Koshikawa, A Yamaguchi, et al (2008) ROS-generating mitochondrial DNA mutations can regulate tumor cell metastasis. Science 320(5876): 661-664.

53. Kumar B, S Koul, L Khandrika, RB Meacham, HK Koul (2008) Oxidative stress is inherent in prostate cancer cells and is required for aggressive phynotype. Cancer Res 68(6): 1777-1785.

54. Demir E, B Kaya, C Soriano (2011) Genotoxic analysis of four lipidperoxidation products in the mouse lymphoma assay. Mutat. Res 726(2): 98-103.

55. Mehta A, RS Verma, N Srivastava (2009) Chlorpyrifos induced alterations in the levels of hydrogen peroxide, nitrate and nitrite in rat brain and liver. Pestic Biochem Physiol 94(2-3): 55-59.

56. Verma RS, A Mehta, N Srivastava (2009) Comparative studies on Chlorpyrifos-and methylparathion- induced oxidative stress in different parts of rat brain: Attenuation by antioxidant vitamins. Pestic Biochemi Physiol 95(3): 152-158.

57. Mansour SA, A Mossa (2009) Lipid peroxidation and oxidative stress in rat erythrocytes induced by chlorpyrifos and protective effect of Zinc. Pestic Biochem Physiol 93(1): 34-39.

58. Kalendar Y, S Kaya, D Durak, FG Uzun, F Demir F (2012) Protective effects of catechin and quercetin on antioxidant status, lipid peroxidation and testis-histoarchitecture induced by chlorpyrifos in male rats. Environ Toxicol Pharmacol 32(2): 141-148.

59. Attia AA, RH ElMazoudy, NS El-Shenawy (2012) Antioxidant role of propolis extract against oxidative damage of testicular tissue induced by insecticide chlorpyrifios in rats. Pestic Biochem Physiol 103(2): 87-93.

60. Elsharkawy EE, D Yahia, NA El Nisr (2013) Sub-chronic exposure to chlorpyrifos induces heamatological, metabolic disorders and oxidative stress in rat: attenuation by glutathione. Environ Toxicol Pharmacol 35(2): 218-227.

61. Bebe FN, M Panemangalore (2013) Exposure to low doses of endosulfan and chlorpyrifos modifies endogenous antioxidants in tissues of rats. J Environ Sci Health B 38(3): 349-363. 
62. Hunt CR, JE Sim, SJ Sullivan, T Featherstone, C Von Kapp-Herr, et al. (1998) Genomic instability and catalase gene amplification induced by chronic response to oxidative stress. Cancer Res 58(17): 3986-3992.

63. Arthur JR (2000) The glutathione peroxidases. Cell Moll Life Sci 57(1314): 1825-1835.

64. Lauterburg BH, ME Velez (1998) Glutathione deficiency in alcoholics: risk factor for paracetamol hepatotoxicity. Gut 29(9): 1153-1157.

65. Edwards R, DP Dixon, V Walbot (2000) Plant glutathione S-transferases: enzymes with multiple functions in sickness and in health. Trends in plant Sci 5 (5): 193-198.

66. Binková B, P Strejc, O Boubelík, Z Stávková, I Chvátalová,, et al. (2001) DNA adducts and human atherosclerotic lesions. International Journal of Hygene and Environmental Health 204(1): 49-54.

67. Hodgson E, RL Rose (2008) Metabolic interactions of Agrochemicals in humans. Pest Manag Sci 64(6): 617-621.

68. Flakos J (2012) The developmental neurotoxicity of organophosphorus insecticides: A direct role for the oxon metabolites. Toxicol Lett 209(1): 86-93.

69. Li J, G Pang, F Ren, B Fang (2019) Chlorpyrifos-induced reproductive toxicity in rats could bee partly relieved under high-fat diet. Chemosphere. 229: 94-102.

70. Kaplan JG, J Kessler, N Rosenberg (1993) Sensory neuropathy associated with Dursban (Chlorpyrifos) exposure. Neurol 43(11): 2193-2196.

71. Gotoh M, I Saito, J Huang, Y Fukaya, T Matsumoto, et al. (2001) Changes in cholinesterase activity, nerve conduction velocity, and clinical signs and symptoms in termite control operators exposed to chlorpyrifos. J Occup Health 43(3): 157-164.

72. Farag AT, AM El Okazy, AF El-Aswd (2003) Developmental toxicity study of chlorpyrifos in rats. Reprod Toxicol 17(2): 203-208.

73. Cutler GC, J Purdy, JP Giesy, KR Solomon (2014) Risk to pollinators from the use of chlorpyrifos in the United States. Rev Environ Contam Toxicol 231: 219-265.
74. Colović MB, DC Krstić, TD Lazarević-Pašti, AM Bondžić, VM Vasić (2013) Acetylcholinesterase inhibitors: pharmacology and toxicology. Current neuropharmacol 11(3): 315-335.

75. Song X, JD Violin, FJ Seidler, T Slotkin (1998) Modeling the developmental neurotoxicity of chlorpyrifos in vitro: macromolecule synthesis in PC12 cells. Toxicol Appl Pharmacol 151(1): 182-191.

76. Slotkin TA (2004) Guidlines for developmental neurotoxicity and their impact on organophosphate pesticides: a personal view from an academic perspective. Neurotoxicol 25(4): 631-640.

77. Slotkin TA., ED Levin, FJ Seidler (2006) Comparative developmental neurotoxicity of organophosphate insecticides: effects on brain development are separable from systemic toxicity. Environ Health Perspect 114: 746-751.

78. Qiao D, FJ Seidler, S Padilla, TA Slotkin (2002) Developmental neurotoxicity of chlorpyrifos: What is the vulnerable period? Environ Health Perspect 110(11): 1097-1103.

79. California Environmental Protection Agency (2008) Evidence on the developmental and reproductive toxicity of chorpyrifos. Reproductive and Cancer hazard Assessment Branch, California Environmental Protection Agency, California, USA.

80. Sandoval L, A Rosca, A Oniga, A Zambrano, JJ Ramos, et al. (2019) Effects of chlorpyrifos on cell death and cellular phenotypic specification of human neural stem cells. Sci Total Environ 683: 445-454.

81. Lieberman AD, MR Craven, HA Lewis, JH Nemenzo (1998) Genotoxicity from domestic use of organophosphate pesticides. J Occup Environ Med 41(6): 416-418.

82. Yu F, Z Wang, B Ju, J Wang, D Bai, et al. (2008) Apoptotic effects of organophosphorus insecticide chlorpyrifos on mouse retina in vivo via oxidative stress and protection of combination of vitamins $\mathrm{C}$ and $\mathrm{E}$. Exp Toxicol Pathol 59(6): 415-423. 